\title{
BERILOS DE PEGMATITOS DE SANTA MARIA DE ITABIRA, MINAS GERAIS - BRASIL
}

\author{
Vitória Régia P.R.O. Marciano(*), Francisco Javier Rios(**), Adriana B. Achtschin(***), \\ José Marques Correia Neves(****) \& Darcy P. Svisero(*****)
}

\begin{abstract}
Samples of beryls from three different pegmatite bodies, representative of the Santa Maria de Itabira region have been studied by several analytical techniques: Color, refraction, luminescence, density, IR spectrum, XRD, cell parameters, fluid inclusions and chemical composition have been considered. The beryls have been analyzed for main elements as well as the following trace elements $\mathrm{Na}, \mathrm{Li}, \mathrm{Cs}, \mathrm{K}, \mathrm{Rb}, \mathrm{Ca}$, $\mathrm{Ba}, \mathrm{Zr}$. Fe e Ti.

The pegmatites described in this paper are situated at the southeastern side of São Francisco Craton and belong to the Eastern Pegmatite Province (PPO). They are related to a magmatism of Brasiliano age. They are being exploited for beryl and gems such as aquamarine, heliodor, colorless topaz and amazonite.

The data are discussed and interpreted from the petrologic and metallogenetic point of view.
\end{abstract}

\section{INTRODUÇÃO}

Santa Maria de Itabira encontra-se a nordeste de Belo Horizonte. $\mathrm{O}$ acesso a ela se faz, a partir da capital do estado de Minas Gerais, pela rodovia BR-262, depois toma-se a MG-434 até a cidade de Itabira, e finalmente, segue-se pela rodovia BR-120.

Neste município estão localizados vários corpos pegmatíticos encaixados discordantemente em rochas gnáissicas da seqüência Rio do Tanque, que pertencem ao complexo gnáissico-migmatítico de Guanhães (Schobbenhaus et al. 1984). Estes pegmatitos estão grosseiramente orientados segundo a direção de fraturas das rochas encaixantes (N60E). A importância deles está relacionada a obtenção de berilo, variedade água marinha.(Figura 1).

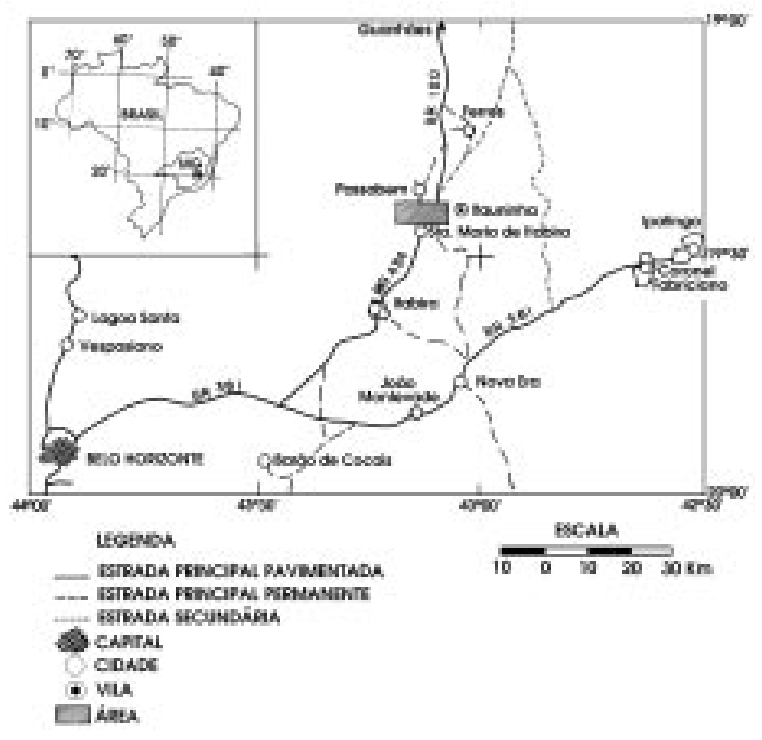

Figura 1: Mapa de localização e acesso à área. Figure 1: Localization sketch of studied area.

\section{OS PEGMATITOS}

Os pegmatitos estudados neste trabalho pertencem à Província Pegmatítica Oriental (PPO) de Minas Gerais (Paiva 1946), e enquadram-se na porção ocidental dela. Esta região, tem sido pouco estudada, entretanto nela ocorre um grande número de corpos pegmatíticos de pequeno a médio porte, sempre explorados devido às gemas neles encontradas.

São corpos predominantemente tabulares, de dimensão média (10 a 30m de comprimento) e espessura de 5 a $10 \mathrm{~m}$, zonados simples, constituídos por quartzo, biotita e/ou muscovita e plagioclásio sódico na zona marginal; intercrescimento gráfico com algumas palhetas de muscovita e granada na zona mural; pertita em cristais euhédricos de 30 a $40 \mathrm{~cm}$ de comprimento e quartzo incolor ou enfumaçado na zona intermédia (Marciano et al. 1992a). A transição entre as zonas se faz de forma gradual, com aumento da dimensão dos grãos. O núcleo na maioria deles não é bem individualizado. Os corpos de substituição são raros e pouco desenvolvidos. No pegmatito da Ponte da Raiz, ocorre fluorita na zona marginal, topázio nos corpos de substituição e o feldspato potássico, em algumas áreas do corpo, se encontra amazonitizado. O principal mineral acessório destes corpos é o berilo, que ocorre em cristais bem formados de coloração verde-azulado, azul (água-marinha) e amarelo (heliodoro). Outros minerais acessórios encontrados são: columbita, samarskita, monazita, bismuto nativo, bismutita, wulfenita, granadas e magnetita.

Cassedane et al. (1993) descrevem nódulos de cosalita acicular envolvidos por bismutita. Estes nódulos chegam a pesar vários quilogramas e apresentam como minerais acessórios pirita, esfalerita e calcopirita. Estes autores citam ainda piromorfita (com As), cerussita, stolzita, picrofarmacolita,

$\left(^{*}\right)$ Centro de Pesquisa Prof. Manoel Teixeira da Costa - I.G.C. - U.F.M.G.

${ }^{\left({ }^{*}\right)}$ Departamento de Geologia - Instituto de Geociências - U.F.Pa.

${ }^{\left({ }^{* \star}\right)}$ Bolsista de Iniciação Científica - CNPq - U.F.M.G.

$\left(^{* * * *)}\right.$ Departamento de Geologia - I.G.C. - U.F.M.G.

$\left({ }^{* \star \star *}\right)$ Instituto de Geociências - U.S.P. 
arsenolita, sulfatos de ferro e enxofre como produtos de alteração dos sulfetos.

Em algumas lavras o processo de intemperismo é pouco intenso, ocorrendo caulinização parcial dos feldspatos, principalmente da fase sódica da pertita, albita, e da biotita. Há um corpo onde a lavra é realizada por desmonte hidráulico devido a caulinização total dos feldspatos. Entretanto, nesta lavra ainda são encontrados cristais de quartzo, muscovita, nióbio-tantalatos, óxidos e hidróxidos de ferro e manganês, além do berilo. Trabalhos de mapeamento da área na escala 1:50.000, com estudo preliminar do corpo da Ponte da Raiz foram coorientados por Marciano (Schettino et al. 1988 e Edim et al. 1988).

A ausência de turmalinas é uma característica marcante dos pegmatitos que ocorrem nesta área, contradizendo a informação de Drumond (1985).

Outras fases minerais mais raras são encontradas associadas aos minerais acima relacionados, sendo comuns sob a forma de inclusões e ou minerais secundários. Destas, pode-se citar uraninita, uranomicrolita como inclusões na columbita, huttonita, cheralita e xenotima na monazita e bavenita no berilo (Tabela 1).

Datação radiométrica através do método K-Ar foi efetuada em muscovita da lavra Morro Escuro. A idade determinada, 519 \pm 10 Ma., sinaliza que estes corpos foram gerados durante o Ciclo Brasiliano, assim como os demais corpos anteriormente datados, pertencentes à Província Pegmatítica Oriental (PPO) (Marciano et al. 1993).
Dentre os feldspatos destaca-se a microclina, quase sempre pertitizada, e a albita. A triclinicidade dos feldspatos potássicos obtida segundo a fórmula proposta por Goldsmith \& Laves (1954) variou entre 0,49 e 0,98 apresentando um valor médio de 0,79 . As amostras analisadas foram obtidas a partir da zona mural (gráfica) e da zona intermédia. O estudo da albita baseou-se na obtenção de sua temperatura de cristalização a partir da diferença entre os produtos dos ângulos $2 \theta$ pela reflexão dos planos reticulares (131) e (13 1) correspondentes através do gráfico proposto por Smith (1974). Esta fase mineral é do tipo (low) formada em um intervalo de temperatura de $200^{\circ} \mathrm{C}$ a $400^{\circ} \mathrm{C}$.

As muscovitas apresentam-se na forma politípica $2 \mathrm{M}_{1}$ e mais raramente segundo associação $2 \mathrm{M}_{1}+1 \mathrm{M}$, esta última quando encontrada ocorre nas bordas ou dentro dos corpos de substituição.

Os nióbio-tantalatos apresentam-se muitas vezes metamictizados e são classificados como columbita e samarskita. Entre as amostras de columbita foram identificados principalmente os politipos desordenados que se cristalizam com abundância de elementos radioativos. Algumas amostras apresentam as reflexões dos planos reticulares (020) e (110) indicativas do politipo ordenado porém com muito baixa intensidade, havendo portanto possibilidade da ocorrência do tipo II, ordenado, nestes pegmatitos.

A análise dos difratogramas de berilos destes corpos classifica-os como politipos $\mathrm{T}_{1}$ onde as substituições de Be por Li são realizadas nas posições tetraédricas . Este politipo é o mais comum (Bakakin et al. 1970).

\begin{tabular}{|c|c|}
\hline ZONA & MNERAIS \\
\hline Marginal & Quartzo, biotita, muscovita, plagioclásio, fluorita, magnetita, granada \\
\hline Mural & Intercrescimento gráfico de quartzo / k-feldspato, berilo \\
\hline Intermediária & Quartzo, k-feldspato \\
\hline Núcleo & Quartzo \\
\hline Unidades de Substituição & $\begin{array}{c}\text { Topázio, berilo, albita, monazita, bismutinita, wulfenita, columbita, } \\
\text { euxenita, samarskita, uraninita, uranomicrolita. }\end{array}$ \\
\hline Minerais Supergênicos e de Alteração & $\begin{array}{c}\text { Caulinita, bavenita, cerussita, stolzita, huttonita, picrofarmacolita, } \\
\text { arsenolita, colsalita, piromorfita, muscovita, sulfato de ferro e enxofre }\end{array}$ \\
\hline
\end{tabular}

Tabela 1. Composição mineralógica dos corpos pegmatíticos da região de Santa Maria de Itabira. Table 1: Mineralogical composition of pegmatites from Santa Maria do Itabira region - MG.

\section{METODOLOGIA EMPREGADA NO ESTUDO DOS MINERAIS}

A difratometria de raios $\mathrm{X}$ foi utilizada tanto na identificação das diferentes fases minerais como na obtenção de formas de classificação, através das propriedades detectadas, capazes de fornecer subsídios para interpretações de índole genética e econômica dos corpos pegmatíticos dessa região. $\mathrm{O}$ difratômetro empregado foi o HZG - 4 da marca Carl Zeiss Iena do CPMTC, tubo de cobre ou cobalto.
Uma das análises por difração de raios $\mathrm{X}$ caracterizou a amostra 4321 como berilo do tipo N, que é aquele cuja composição química se aproxima mais da composição ideal, teórica. Por este mesmo método foram identificadas as reflexões que mostram a associação berilo-bavenita, ocasionada por processo de alteração, com participação da água que atuou sobre o berilo dos corpos pegmatíticos desta região. Os dados obtidos a partir da difratometria de raios $X$ são encontrados na Tabela 2 . 


\begin{tabular}{|c|c|c|c|c|c|}
\hline $\begin{array}{c}\text { FASE } \\
\text { MINERAL }\end{array}$ & AMOSTRA & $\begin{array}{c}\text { POLITIPO } \\
\text { ESTRUTURAL }\end{array}$ & \multicolumn{2}{|c|}{$\begin{array}{c}\text { DADOS DA CÉLULA } \\
\text { UNITÁRIA }\end{array}$} & LAVRA \\
\hline \multirow{4}{*}{ BERILO } & 5064 & $\mathrm{~T} 1$ & $\begin{array}{l}a=9,199 \AA \\
c=9,161 \AA\end{array}$ & $v=671,299 \AA^{3}$ & MORROESCURO \\
\hline & 4321 & $n$ & $\begin{array}{l}a=9,215 \AA \\
c=9,206 \AA\end{array}$ & $v=676,989 \AA^{3}$ & PONTE DA RAIZ \\
\hline & 4857Pr & $\mathrm{T} 1$ & $\begin{array}{l}\mathrm{a}=9,190 \AA \\
\mathrm{c}=9,180 \AA\end{array}$ & $v=671,320 \AA^{3}$ & PONTE DA RAIZ \\
\hline & Ber Pr & $\mathrm{T} 1$ & $\begin{array}{l}a=9,132 \AA \\
c=9,147 \AA\end{array}$ & $\mathrm{v}=660,668 \AA^{3}$ & PONTE DA RAIZ \\
\hline \multirow{2}{*}{ BAVENITA } & BAV-Ber Pr & & $\begin{array}{c}a=9,752 \AA \\
b=11,489 \AA \\
c=4,998 \AA\end{array}$ & $v=559,990 \AA^{3}$ & PONTE DA RAIZ \\
\hline & BAV 4857 & & $\begin{array}{c}a=9,809 \AA \\
b=11,503 \AA \\
c=4,948 \AA\end{array}$ & $V=554,892 \AA^{3}$ & PONTE DA RAIZ \\
\hline
\end{tabular}

Tabela 2: Dados obtidos pela difração de raios $X$ de berilos de Santa Maria de Itabira.

Table 2: X-Ray diffraction data of beryls from Santa Maria do Itabira - MG.

As análises por espectrometria de absorção no infravermelho realizadas por equipamento modelo 283B da Perkin-Elmer, foram utilizadas na identificação dos fluidos encontrados nas diferentes fases minerais. Esta composição é comum para todas as fases, sendo constituída por água, gás carbônico, ocorrendo ainda metano em menor quantidade.

A composição química dos minerais foi determinada pela utilização da combinação de várias metodologias como, fotometria de chama, fluorescência de raios $\mathrm{X}$, espectrometria de emissão atômica por plasma induzido, microscopia eletrônica com EDS, microssonda eletrônica e gravimetria.

Os feldspatos e micas são pobres em metais alcalinos, com baixa relação $\mathrm{K} / \mathrm{Rb}$, característica de pegmatitos pouco evoluídos. Se comparados com outros da Província Pegmatítica Oriental (PPO) abordados por Correia Neves et al. (1986), estes corpos pegmatíticos se mostram os menos diferenciados, e que apresentam o menor conteúdo em $\mathrm{Rb}, \mathrm{Li}$ e $\mathrm{Cs}$, muito semelhantes à muscovitas e feldspatos da Lavra do Ferreirinha, estudados por Marciano (1985). No gráfico da figura 2 as muscovitas são empregadas na classificação das ocorrências pegmatíticas de Santa Maria de Itabira, correlacionando a razão K/Rb ao teor em lítio. Considerando os campos estabelecidos por Cerný \& Burt (1984) neste gráfico, estes corpos estudados seriam transição entre pegmatitos tipo muscovíticos e muscovita-elementos raros, semelhantes a todos os outros da borda ocidental da Província Pegmatítica Oriental (PPO) (Marciano et al. 1992b). Se confrontados com os de Moçambique (Lopes Nunes 1973), tanto pela composição mineralógica quanto pelo quimismo, podem ser enquadrados como sendo de transição entre os tipos potássico e radioativo (Figura 3), com teor em titânio muitas vezes maior do que aqueles estudados por Cerný \& Burt (1984).

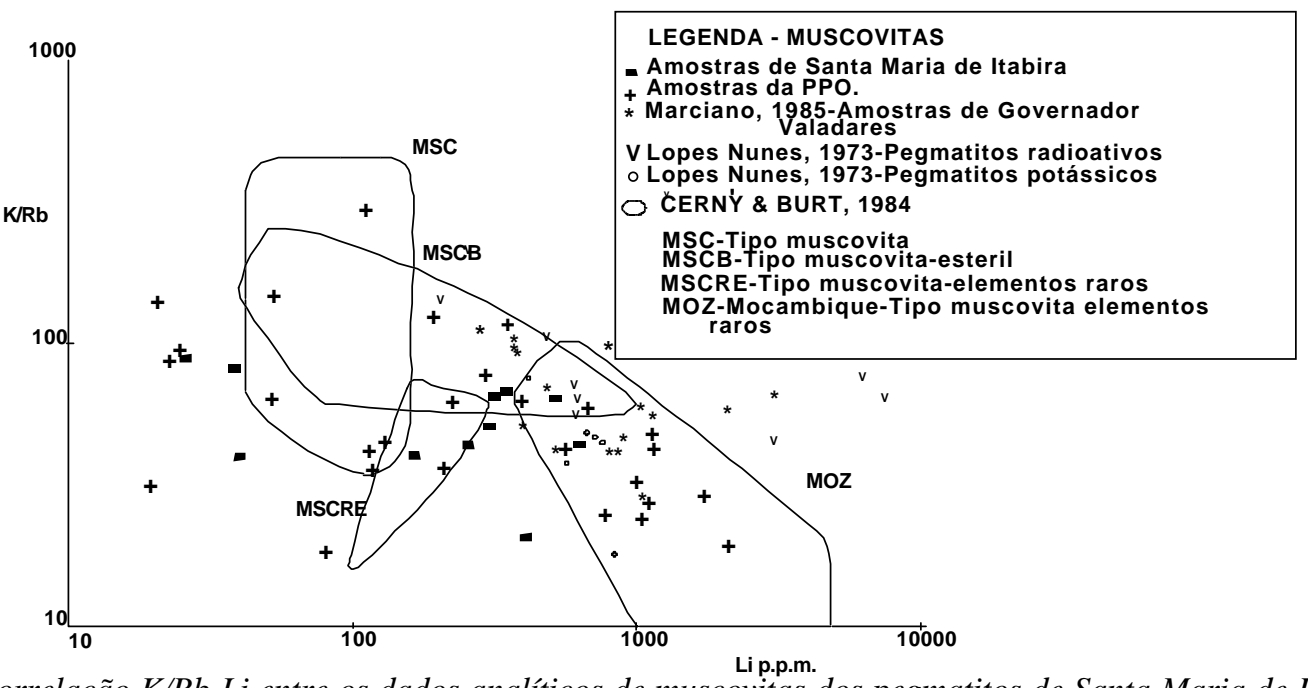

Figura 2: Correlação K/Rb-Li entre os dados analíticos de muscovitas dos pegmatitos de Santa Maria de Itabira com outros da Província Pegmatítica Oriental (PPO), e ainda os campos relativos aos tipos pegmatíticos de Cerný \& Burt (1984).

Figure 2: K/Rb-Li correlation between analytical data of muscovite from Santa Maria do Itabira region with such of the Eastern Pegmatite Province (PPO) showing the fields of pegmatite types after Cerny \& Burt (1984). 


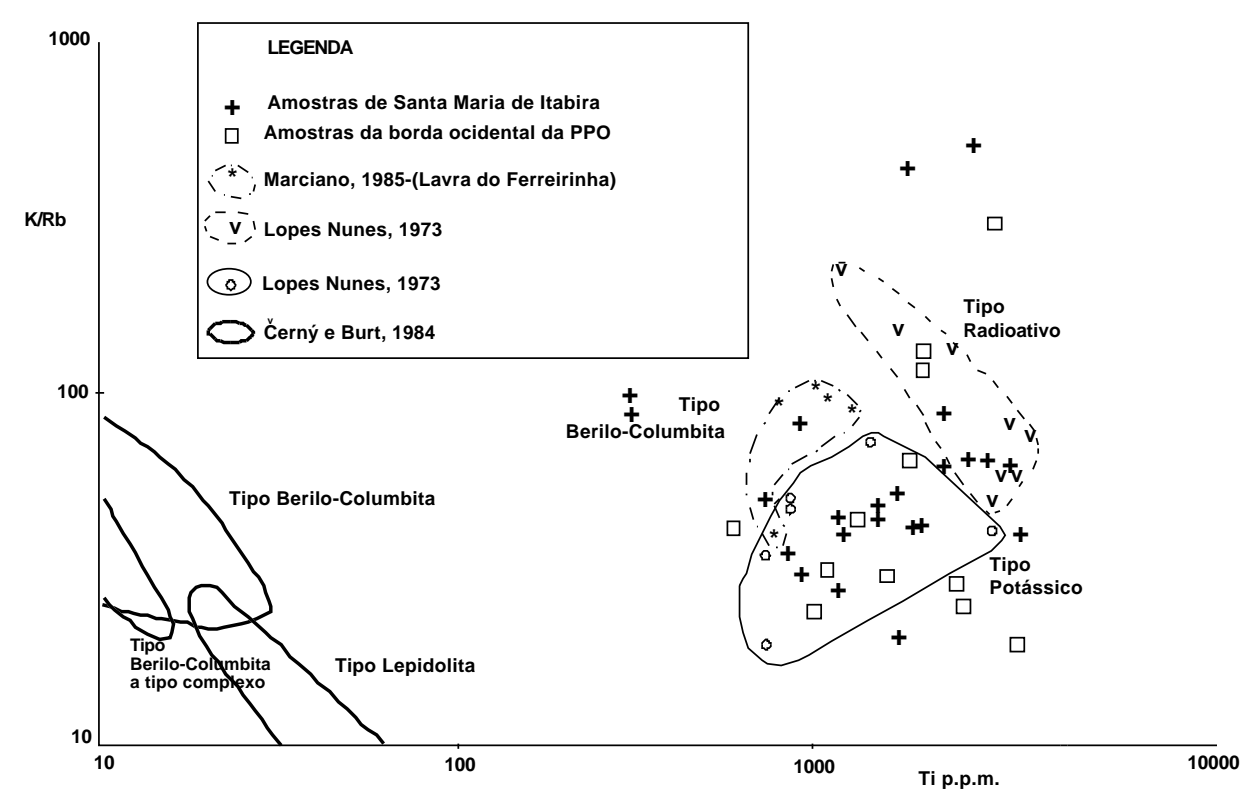

Figura 3: Correlação K/Rb-Ti entre os dados analíticos de muscovitas dos pegmatitos de Santa Maria de Itabira com outros da Província Pegmatítica Oriental (PPO), e ainda os campos relativos aos tipos de pegmatitos de Cerný \& Burt (1984) e de Lopes Nunes (1973).

Figure 3: K/Rb-Li correlation between analytical data of muscovites from Santa Maria do Itabira region with such of the Easterm Pegmatite Province (PPO) showing the fields of pegmatite types after Cerný \& Burt (1984) and Lopes Nunes (1973).

A biotita, na maioria das ocorrências, é encontrada em placas subédricas a anédricas, parcialmente alteradas. As análises químicas executadas pela Geosol mostraram valores baixos para $\mathrm{Mg}^{2+}$, sendo as amostras classificadas como ferro-biotitas. Quando comparadas com análises realizadas por espectroscopia Mössbauer, estas últimas apresentam valores menores para $\mathrm{Fe}^{2+}$. Através desta última metodologia pode-se conhecer a posição exata ocupada pelos cátions $\mathrm{Fe}^{2+}$ e $\mathrm{Fe}^{3+}$, que nestas amostras é sempre octaédrico (Macedo et al. 1994).

Os nióbio-tantalatos foram estudados através de microscopia óptica, microscopia eletrônica de varredura e microssonda eletrônica. $\mathrm{O}$ teor em Ta das amostras da série columbo-tantalita chega a ser igual ao de $\mathrm{Nb}$ e o $\mathrm{Mn}>\mathrm{Fe}$ em amostra da Lavra do Morro Escuro. Entretanto a maioria apresenta $\mathrm{Nb}>\mathrm{Ta}$ e $\mathrm{Fe}$ $>\mathrm{Mn}$, sendo assim classificadas como ferrocolumbitas. Através das análises por microscopia eletrônica com utilização do sistema de dispersão de energia (EDS) foram identificadas várias inclusões e vênulas de minerais contendo urânio, tório, chumbo e elementos de terras-raras, como monazita, torita, tengerita, cerussita, uranomicrolita, galena. $\mathrm{O}$ outro mineral do grupo dos nióbio-tantalatos é a samarskita, que ocorre em cristais anédricos associada à monazita (Marciano et al. 1992c).

O único fosfato encontrado, em amostras bem desenvolvidas, foi a monazita, que ocorre em cristais prismáticos de até $8 \mathrm{~cm}$ de comprimento. Processos de alteração secundária atuaram sobre as bordas dos cristais de monazita transformando-a em huttonita. Ocorre nela ainda inclusões de xenotima, cheralita e minerais de $\mathrm{U}$ e $\mathrm{Th}$.

As análises de microscopia eletrônica foram realizadas nos laboratórios da CBMM em Araxá, M.G. e as de microssonda eletrônica na Escola de Minas de Paris - França, tanto para as monazitas como para os nióbio-tantalatos (Bilal et al. 1993a e b).

\section{OS BERILOS}

O mineral de maior importância nestes corpos pegmatíticos é o berilo, sendo esta espécie mineral a responsável pelos trabalhos de lavra em toda a região do Vale do Alto Rio Doce.

Duas gerações de berilo podem ser discriminadas nestes pegmatitos. Aquela que ocorre na zona gráfica grosseira ou zona intermédia, caracterizada por cristais bem desenvolvidos, que alcançam dimensões decamétricas. São opacos, com coloração azulada ou esverdeada, apresentando-se na forma prismática. A designação "escória" é usualmente empregada pelos garimpeiros para amostras que apresentam este aspecto e sua importância econômica está ligada a obtenção do Be. A região central destes cristais contêm, por vezes, porções transparentes de água marinha de qualidade gemológica. Esta geração de berilo se associa a feldspato potássico pertitizado, quartzo e muscovita em "livros" de até $15 \mathrm{~cm}$. Os cristais que ocorrem nas unidades de substitução são, via de regra, terminados por pinacóides, raras vezes por dipirâmides bem menores que os anteriores. Esses têm como paragênese albita, freqüentemente na variedade clevelandita, quartzo, muscovita de segunda geração em cristais de cerca de 2 a $3 \mathrm{~cm}$, topázio, granada e 
outros. Apresentam-se com cores azul, variedade água marinha e amarelo, variedade heliodoro. A tabela 3 relaciona dados de duas amostras de berilo, ambos da Lavra Ponte da Raiz. Nesta ocorrência os minerais de cor amarela (heliodoro) se encontram em cristais com 1 a $2 \mathrm{~cm}$ de diâmetro, anédricos, arredondados, mais raros que as demais variedades. Entretanto foi retirado de lá um cristal prismático de $8 \mathrm{~cm}$ de comprimento por $2 \mathrm{~cm}$ de largura. Os dados obtidos para esses minerais são bem semelhantes àqueles obtidos por Lahti \& Kinnunen (1993), provenientes do pegmatito Luumäki na Finlândia. de toda a Província Pegmatítica Oriental (PPO), só semelhantes aos da Lavra do Ferreirinha, em Governador Valadares, e a alguns provenientes de pegmatitos da borda ocidental da PPO.

As relações percentagem de $\mathrm{SiO}_{2}$ com teores em ppm de Li, Cs e total de álcalis visualizados na Figura 5, mais uma vez confirmam que estes berilos são muito pobres nestes elementos, e que também apresentam valores inferiores àqueles encontrados para os berilos da Lavra da Generosa, exceto quanto ao Cs, cujo teor é mais baixo nesta última ocorrência. As áreas salientadas nos gráficos são relativas aos corpos

\begin{tabular}{|cc|c|}
\hline $\begin{array}{c}\text { Amostra } \\
\text { Cor }\end{array}$ & $\begin{array}{c}4321 \\
\text { Azul }\end{array}$ & $\begin{array}{c}4857 \\
\text { Amarelo }\end{array}$ \\
\hline Variedade & Água Marinha & Heliodoro \\
\hline Índice de Refração & $\mathrm{n} e=1,574$ & $\mathrm{n} e=1,574$ \\
$\mathrm{n} \mathrm{w}=1,580$ & $\mathrm{n}=1,579$ \\
Birrefringência & $\mathrm{n}=0,006$ & $\mathrm{n}=0,005$ \\
Caráter Óptico & Uniaxial Negativo & Uniaxial Negativo \\
\hline Luminescência & Inerte tanto sob & Inerte tanto sob \\
à Radiação U.V. & comprimento de radiação & comprimento de radiação \\
longo como curto & longo como curto \\
\hline Peso Específico & 2,699 & 2,678 \\
\hline
\end{tabular}

Tabela 3. Propriedades físicas dos berilos da Lavra Ponte da Raiz, Santa Maria de Itabira, M.G. Table 3: Physical properties of beryls from Lavra Ponte da Raiz, Santa Maria do Itabira, MG.

\section{QUIMISMO DOS BERILOS}

O conhecimento do conteúdo em álcalis e água nos berilos está intimamente correlacionado com as características geoquímicas e paragenéticas dos sistemas geológicos onde são gerados. Cerný (1975) modificou a classificação anteriormente estabelecida por Beus (1960), baseada na quantidade de álcalis, propondo a subdivisão dos berilos de pegmatitos em cinco tipos. As análises químicas obtidas neste trabalho possibilitam o enquadramento destes minerais entre os do tipo I, berilos sem álcalis que apresentam a soma de álcalis total menor que $1 \%$ em peso, e os do tipo III, berilos sódicos, aqueles que o sódio é o álcali predominante, com teores variando entre 0,5 e $1 \%$. Utilizando o diagrama proposto por Trueman \& Cerný (1982) verifica-se que os pontos relativos às análises dos berilos da região estudada, localizam-se muito próximos à linha da ordenada, no campo A, que se refere a berilos oriundos de pegmatitos estéreis e portadores de $\mathrm{Be}, \mathrm{Nb}$, Ta, pobres em álcalis raros (Figura 4). Estas duas citações de categorias para berilos e pegmatitos são confirmadas pelos aspectos já mencionados nos parágrafos relativos à mineralogia destes corpos por nós estudados. Da comparação destes dados com outros referidos por Correia Neves et al. (1984) e Marciano (1985) nota-se que os berilos de Santa Maria de Itabira são os mais pobres em álcalis pegmatitos de maiores dimensões que ocorrem na borda ocidental da PPO.

\section{INCLUSÕES FLUIDAS DOS BERILOS}

Com o objetivo de se conhecer o papel da temperatura na formação do mineral, lançou-se mão do estudo das inclusões fluidas (IF). Essa metodologia já vem sendo empregada por vários autores em berilo desde o final da década de 40 (Roedder 1951; Cameron et al. 1951; Cameron et al. 1953; Sinkankas 1981; Souza \& Svisero 1987; Souza et al. 1987; Souza 1989; Mendes 1989; Souza et al. 1990; Lathi \& Kinnunen 1993). Para tanto foram preparadas duas lâminas delgadas e três seções bipolidas do berilo 4858, proveniente da Lavra Ponte da Raiz.

Utilizou-se para o estudo petrográfico e microtermométrico um microscópio Leitz Laborlux 12 Pol 5 - acoplado a uma câmara clara. A platina de aquecimento-resfriamento $\left(+600^{\circ} \mathrm{C} /-180^{\circ} \mathrm{C}\right)$ é um modelo 818 P 15 da Chaimeca-Eurotherm do Centro de Pesquisa Professor Manoel Teixeira da Costa da UFMG.

O mapeamento realizado sob microscópio indicou a existência de três tipos diferentes de inclusões fluidas: primárias, pseudo-secundárias e secundárias (Achtschin et al. 1994). (Fotos 1,2 e 3) 

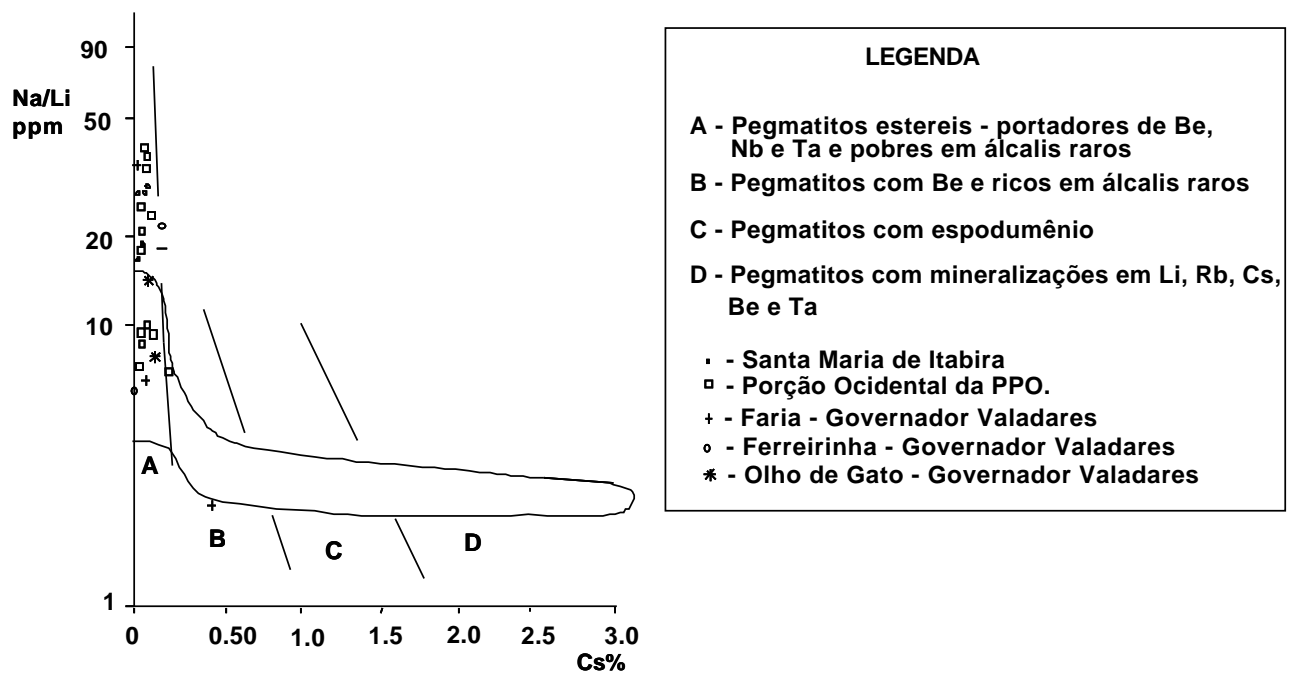

Figura 4: Classificação dos pegmatitos baseada nas análises químicas dos berilos, segundo Trueman \& Cerný (1982).

Figure 4: Classification of pegmatites based on chemical analysis of beryls, after Trueman \& Cerný (1982).
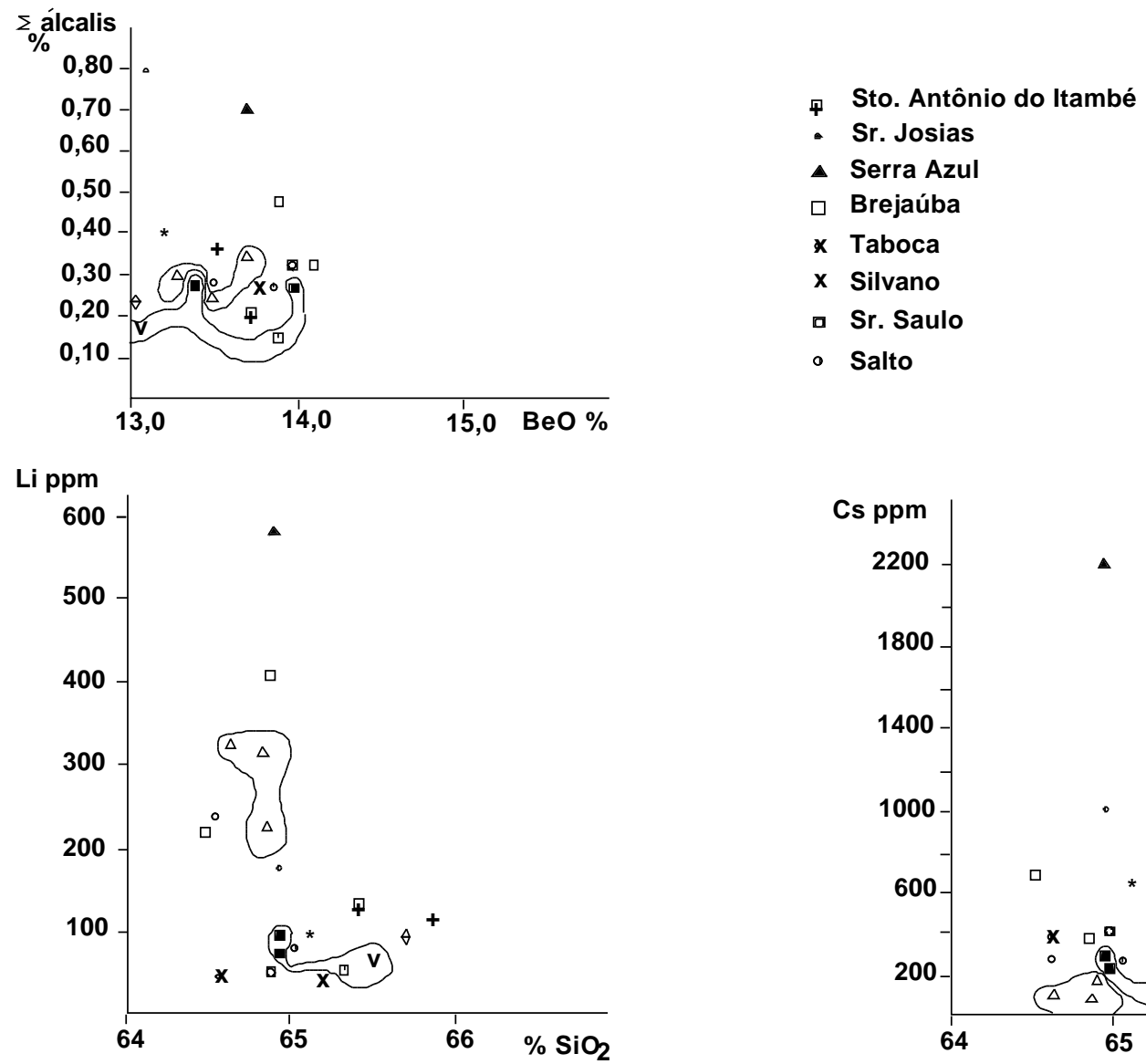
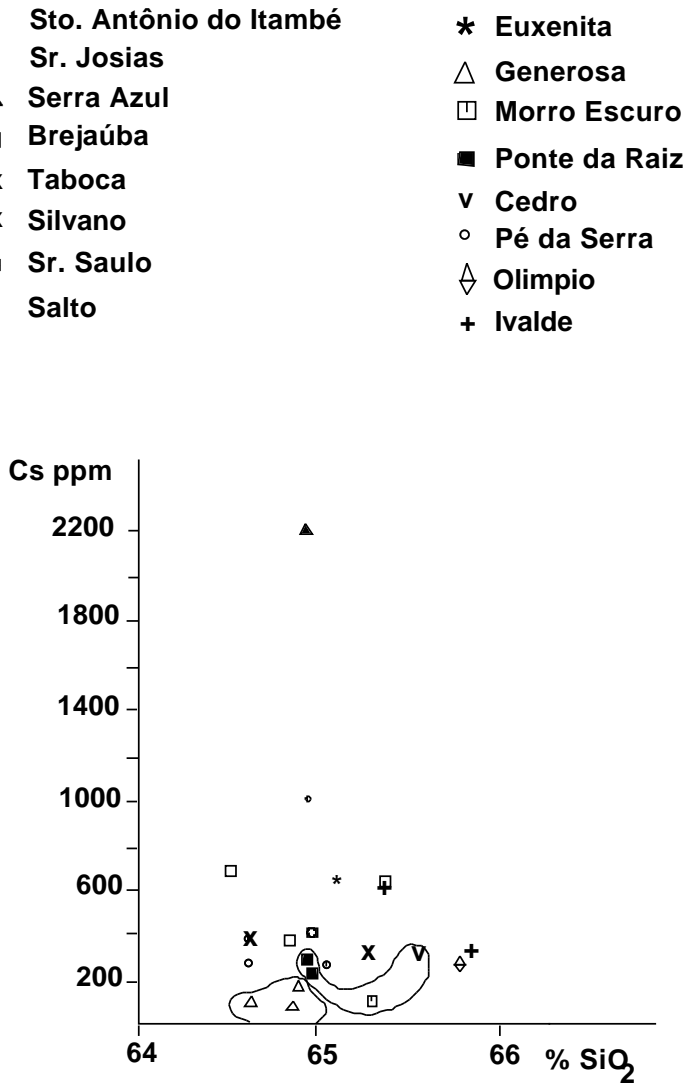

Figura 5: Relação \%BeO/total de álcalis; \% $\mathrm{SiO}_{2}$ / Li; \% $\mathrm{SiO}_{2}$ / Cs em p.p.m., nos berilos da lavra Ponte da Raiz comparados com outros de Santa Maria de Itabira e de outras regiões na borda ocidental da PPO.

Figure 5: Relation ship BeO/total alcalis, $\mathrm{SiO}_{2} / \mathrm{Li}$; $\mathrm{SiO}_{2} / \mathrm{Cs}$ ration, of beryls from Lavra Ponte da Raiz,, compared with such from Santa Maria do Itabira and others regions of Eastern Pegmatite Province (PPO). 


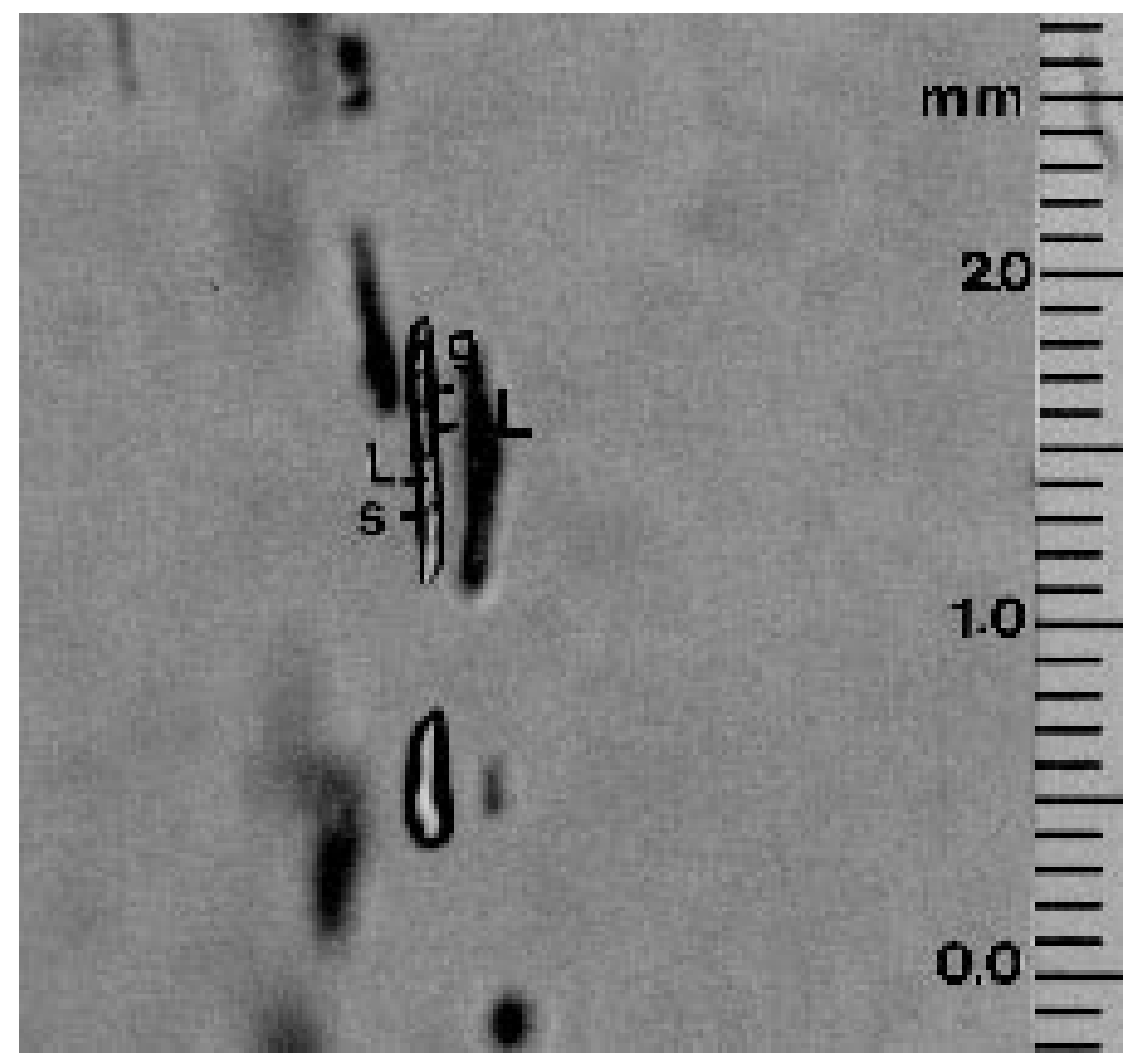

Foto 1: Fotomicrografia - Alinhamentos de inclusões fluidas aquo-carbônicas (monofásicas, bifásicas e polifásicas) de caráter possivelmente pseudosecundário.

Photo 1: Linear arrangement of water/ $\mathrm{CO}_{2}$ fluid inclusions possibly pseudo-secondary.

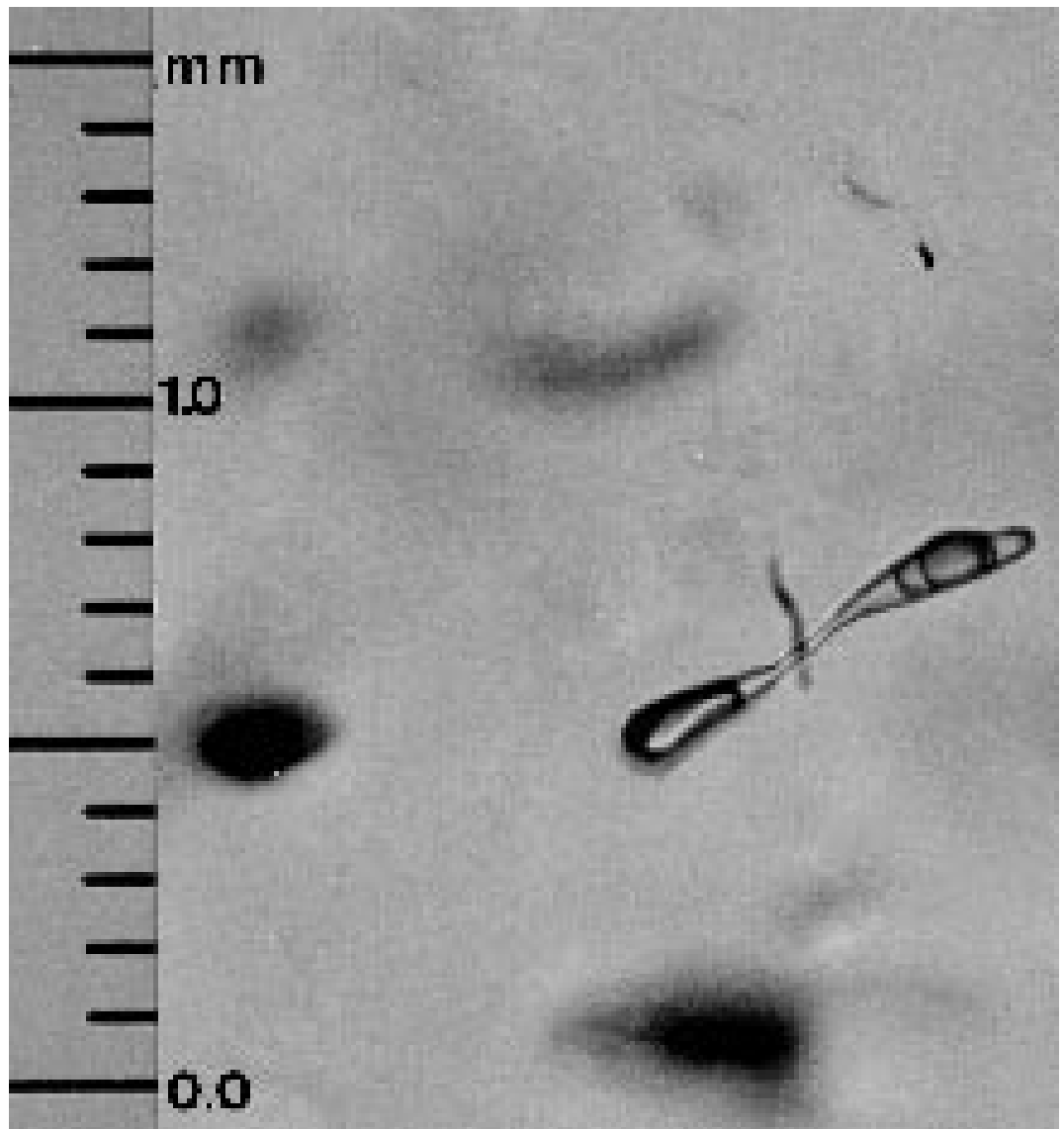

Foto 2: Fotomicrografia - Inclusões fluidas primárias aquo-carbônicas em processo de estrangulamento (a partir de uma inclusão fluida originam-se duas inclusões da mesma composição). Photo 2: Splitting of water/CO $\mathrm{O}_{2}$ primary fluid inclusions. 


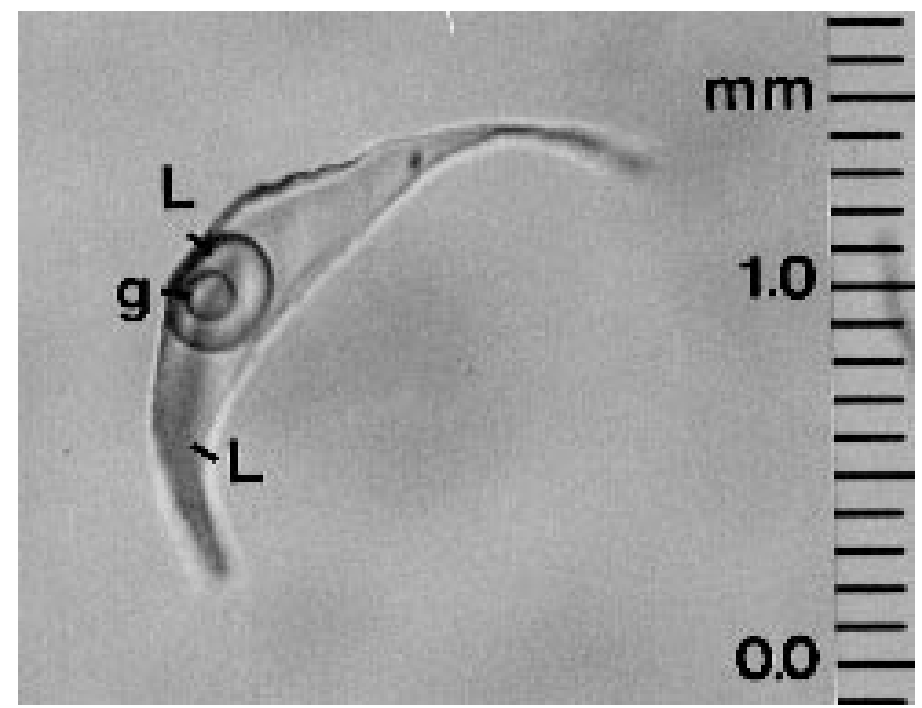

Foto 3: Fotomicrografia - Inclusão fluida primária a $25^{\circ} \mathrm{C}$. Nota-se o caráter trifásico desta inclusão $\left(\mathrm{L}_{\mathrm{H}_{2} \mathrm{O}}+\mathrm{L}_{\mathrm{CO}_{2}}+\mathrm{G}_{\mathrm{CO}_{2}}\right)$ à temperatura ambiente.

Photo 3: Primary fluid inclusions at $25^{\circ} \mathrm{C}$.

As inclusões primárias apresentam-se sob formas de tubo, na de cristal negativo, estão orientadas paralelas ao eixo cristalográfico c. As primeiras têm dimensões geralmente inferiores a $10 \mu \mathrm{m}$, enquanto as outras, bem maiores, alcançam até $20 \mu \mathrm{m}$. Ocorrem ainda nesta categoria inclusões sub arredondadas, que são menos freqüentes. Neste grupo predominam as inclusões fluidas bifásicas $(\mathrm{L}+\mathrm{G})$, embora possam ser encontradas monofásicas (L?) e trifásicas $(\mathrm{L}+\mathrm{L}+\mathrm{G})$ ou $(\mathrm{L}+\mathrm{G}+\mathrm{S})$. As fases sólidas $(\mathrm{S})$ podem apresentar formas retangulares e pseudo hexagonais. O volume da fase gasosa $(\mathrm{G})$ é variável, podendo chegar a ocupar $50 \%$ do volume total da inclusão. A microtermometria confirmou a composição aquo-carbônica destas inclusões fluidas concordando com os dados obtidos por espectrografia infravermelho. Durante o resfriamento, daquelas IF desprovidas de fases sólidas, a fusão do $\mathrm{CO}_{2}$ ( $\mathrm{Tf} \mathrm{CO}_{2}$ ) ocorreu, invariavelmente, entre $-56,4^{\circ}$ e $-56,8^{\circ} \mathrm{C}$. Já no aquecimento foi possível inferir a temperatura de fusão de clatratos (Tf CL) entre $6,2^{\circ}$ e $6,4^{\circ} \mathrm{C}$. Estes valores permitem calcular a salinidade aproximada da fase aquosa, que é equivalente a aproximadamente $8 \%$ em peso de $\mathrm{NaCl}$ (Collins 1979). A homogeneização da fase gasosa de $\mathrm{CO}_{2}\left(\mathrm{Th} \mathrm{CO}_{2}\right.$ ) ocorreu sempre próximo dos $31^{\circ} \mathrm{C}$. As IF sub-arredondadas começam a homogeneizar totalmente (Th tot) a $310^{\circ} \mathrm{C}$ e continuam até $460^{\circ} \mathrm{C}$. Acima desta temperatura algumas IF tubulares ainda não haviam se homogeneizado. Não foi observada crepitação nas IF primárias.

Numa próxima etapa deverão ser estudadas as fases sólidas as IF trifásicas $(\mathrm{L}+\mathrm{G}+\mathrm{S})$. Estas fases não são birrefringentes e possivelmente sejam cristais de saturação. Segundo Lathi \& Kinnunen (1993), todo o potássio existente nos berilos ocorre como cristais de saturação, consequentemente, de acordo com as análises químicas, devem ser halita e silvita.

As inclusões fluidas pseudo-secundárias apresentam formas semelhantes as das IF primárias, embora ocorram sempre orientadas. Estes alinhamentos aparentemente não ultrapassam as dimensões dos cristais hospedeiros, motivo pelo qual foram classificadas como pseudo secundárias. O mapeamento não confirmou se algumas destas direções correspondem a linhas de crescimento do berilo. A natureza do fluido destas inclusões é aquo-carbônica e são semelhantes em composição às IF primárias. Podem ser monofásicas, bifásicas e até multifásicas. Dentro deste grupo foi possível distinguir 3 tipos de IF que se diferenciam somente pelas características das fases sólidas. Um primeiro tipo apresenta inclusões com uma única fase sólida anédrica. No segundo, as IF apresentam vários cristais da mesma fase sólida. O terceiro tipo apresenta fases sólidas não birrefringentes (cristais de saturação), de formas poligonais que podem chegar a ocupar $80 \%$ do volume total da inclusão. Estes tipos de IF não ocorrem misturados no mesmo alinhamento. Estão vinculados à direções diferentes, mas em nenhuma delas foi possível confirmar um caráter secundário.

Durante o resfriamento nas IF bifásicas, trifásicas e multifásicas foi observada $\mathrm{Tf}_{\mathrm{CO}_{2} \text { a }}-56,8^{\circ} \mathrm{C}$.

Durante o aquecimento foi estimada em várias destas IF a $\mathrm{Tf} \mathrm{CL}$ a $7,0^{\circ} \mathrm{C}$. Este valor indica que a salinidade da fase aquosa é equivalente a aproximadamente $5 \%$ em peso de $\mathrm{NaCl}$. A $\mathrm{Th}^{\mathrm{CO}_{2}}$ ocorreu na fase líquida, a temperaturas entre $16,7^{\circ} \mathrm{e}$ $31,0^{\circ} \mathrm{C}$. Já Th tot começou por volta dos $300^{\circ} \mathrm{C}$ e continuou até $410^{\circ} \mathrm{C}$. Nas IF multifásicas a homogeneização total da fase gasosa não ulrapassou os $315^{\circ} \mathrm{C}$.

As inclusões secundárias atravessam os cristais de berilo segundo alinhamentos irregulares e se continuam em outros minerais do pegmatito como nos feldspatos. Esses alinhamentos estão diretamente relacionados a microfraturamentos posteriores à 
formação do cristal, ao longo dos quais, antes do fechamento e suturação, percolaram fluidos tardios.

Estas inclusões apresentam formas extremamente variadas (sub-arredondadas, estreladas, amebóides, etc.). Podem ser monofásicas (L), bifásicas e trifásicas $(\mathrm{S}+\mathrm{L}+\mathrm{G})$. Foram estudadas IF aquosas, que aparentemente não apresentam $\mathrm{CO}_{2}$. Durante os testes de resfriamento algumas delas apresentaram um comportamento metaestável. Na IF bifásicas que não apresentaram metaestabilidade foi possível registrar a Te em torno de $-20^{\circ} \mathrm{C}$, o que indica que o fluido corresponde ao sistema salino $\mathrm{H}_{2} \mathrm{O}-\mathrm{NaCl}$ (Crawford 1981). A fusão do gelo ocorre entre $-3,5^{\circ}$ e $-2,0^{\circ} \mathrm{C} \mathrm{o}$ que indica que os fluidos possuem salinidade baixa, equivalente a 3,4-5,7\% em peso de $\mathrm{NaCl}$ (Bodnar \& Vitykl 1994). Não foi determinada a Th destas IF, mas este valor dificilmente deve ultrapassar os $200^{\circ} \mathrm{C}$.

As inclusões fluidas monofásicas, provavelmente secundárias e em forma de tubo, relacionadas a outros alinhamentos secundários, também foram estudadas microtermometricamente. Durante o refriamento foi possível estimar a temperatura do ponto eutético (Te) perto dos $-35^{\circ} \mathrm{C}$ apontando para a provável existência de $\mathrm{Fe}^{++}$ou $\mathrm{Na}^{+}$e $\mathrm{Mg}^{++}$no sistema (Roedder 1984). A temperatura de fusão do gelo (Tf gelo) ocorreu entre $3,5^{\circ}$ e $-0,9^{\circ} \mathrm{C}$, o que indica para esta IF salinidades equivalentes a 1,4-5,7\% em peso de $\mathrm{NaCl}$. A continuidade destes estudos confirmará, ou não, a presença de $\mathrm{CO}_{2}$ ou alguma outra fase molecular nestas inclusões (Tabela 4).

\section{CONCLUSÕES}

Os berilos de pegmatitos de Santa Maria de Itabira são pobres em álcalis e apresentam formas politípicas T ou N (Babakin et al. 1970). Segundo a classificação de Cerný (1975) são sódicos. Em sua maioria são empregados como fonte de berílio ou como gemas nas variedades água-marinha e heliodoro. Ocorrem associados a microclina, muscovita, biotita, quartzo, nióbio-tantalatos ricos em $\mathrm{Nb}$, fluorita, monazita e topázio entre outros. Os pegmatitos portadores destes berilos são do tipo A, pegmatitos estéreis portadores de $\mathrm{Be}, \mathrm{Nb}$, Ta e pobres em álcalis raros (Trueman \& Cerný 1982). Os fluidos primários estudados nos berilos apresentam composição no sistema $\mathrm{H}_{2} \mathrm{O}-\mathrm{CO}_{2}-\mathrm{NaCl}$, já os fluidos secundários são de composição aquosa (provavelmente sem $\mathrm{CO}_{2}$ ), podendo ocorrer ainda $\mathrm{CH}_{4}$. A cristalização desse mineral ocorreu em um intervalo de temperatura entre $310^{\circ}$ e $460^{\circ} \mathrm{C}$ que corresponde à temperatura de formação do final da zona mural e zona intermédia, muito semelhante à do pegmatito Luumäki que ocorreu entre $400^{\circ}$ e $490^{\circ} \mathrm{C}$; e que apresenta similaridade na composição mineralógica.

\section{AGRADECIMENTOS}

Somos gratos às Agências Financiadoras, Fapemig, CNPq e à UFMG pela possibilidade de termos os meios necessários para desenvolver este trabalho. Em especial, agradecemos ao Dr. Kazuo Fuzikawa pela orientação dada na área relativa ao estudo das inclusões fluidas.

\begin{tabular}{|c|c|c|c|}
\hline Classificação & Inclusões Fluidas Primárias & $\begin{array}{l}\text { Inclusões Fluidas Pseudo } \\
\text { Secundárias }\end{array}$ & Inclusões Fluidas Secundárias \\
\hline Forma & $\begin{array}{c}\text { Tubulares } \\
\text { Cristais Negativos } \\
\text { Subarredondadas }\end{array}$ & $\begin{array}{l}\text { Semelhantes às inclusões } \\
\text { primárias }\end{array}$ & $\begin{array}{l}\text { Subarredondadas } \\
\text { Estreladas } \\
\text { Amebóides }\end{array}$ \\
\hline Dimensão & $\begin{array}{c}\text { Tubulares }<10 \mu \mathrm{m} \\
\text { Subarredondadas atingem } 20 \mu \mathrm{m}\end{array}$ & & \\
\hline Fases & $\begin{array}{c}\text { Monofásicas }(\mathrm{L}) \\
\text { Trifásicas }(\mathrm{L}+\mathrm{L}+\mathrm{G}) \text { ou }(\mathrm{L}+\mathrm{V}+\mathrm{G}) \\
\text { Polifásicas }(\mathrm{L}+\mathrm{L}+\mathrm{G}+\mathrm{S})\end{array}$ & $\begin{array}{c}\text { Monofásicas }(\mathrm{L}) \\
\text { Bifásicas }(\mathrm{H} 2 \mathrm{O} \text { e } \mathrm{CO} 2 \\
\text { Polifásicas }(\mathrm{L}+\mathrm{L}+\mathrm{G}+\mathrm{S})\end{array}$ & $\begin{array}{c}\text { Monofásicas (S ou L) } \\
\text { Bifásicas } \\
\text { Trifásicas }(S+L+V)\end{array}$ \\
\hline Distribuição & $\begin{array}{l}\text { Paralelas ao eixo c } \\
\text { aleatórias }\end{array}$ & $\begin{array}{l}\text { Alinhadas segundo direções, } \\
\text { não bem definidas }\end{array}$ & Ao longo de fraturas irregulares \\
\hline Composição & $\mathrm{H}_{2} \mathrm{O}, \mathrm{CO} 2_{2}^{\mathrm{e} \text { Sólidos }}$ & $\mathrm{H}_{2} \mathrm{O}, \mathrm{CO}_{2}$ e Sólidos & $\mathrm{H}_{2} \mathrm{O}\left(\mathrm{CO}_{2} ?\right)$ \\
\hline $\begin{array}{c}\text { Medidas } \\
\text { Termométricas }\end{array}$ & $\begin{array}{c}\text { Tf } \mathrm{CO}_{2}-56,4 \text { a }-56,8^{\circ} \mathrm{C} \\
\text { Tf CL } 6,2 \text { a } 6,4^{\circ} \mathrm{C}\end{array}$ & $\begin{array}{r}\text { Tf } \mathrm{CO}_{2}-56,8^{\circ} \mathrm{C} \\
\text { Tf } \mathrm{CL} 7^{\circ} \mathrm{C}\end{array}$ & $\begin{array}{l}\text { Te }-35^{\circ} \mathrm{C} \text { Monofásicas } \\
\text { Tf gelo }-3,5^{\circ} \mathrm{C} \text { a } 0,9^{\circ} \mathrm{C}\end{array}$ \\
\hline Salinidade & $8 \%$ Peso $\mathrm{NaCl}$ & $5 \%$ Peso $\mathrm{NaCl}$ & $4-6 \%$ Peso $\mathrm{NaCl}$ \\
\hline $\begin{array}{l}\text { Temperatura de } \\
\text { Homogeneização }\end{array}$ & $\begin{array}{c}\text { THCO } 2^{-31^{\circ} \mathrm{C} \text { (gasosa) }} \\
\text { TH Tot } 310 \text { a } 460^{\circ} \mathrm{C} \\
\text { (subarredondadas) }\end{array}$ & $\begin{array}{c}\text { TH CO } 26,7 \text { a } 31^{\circ} \mathrm{C} \text { (liquida) } \\
\text { TH Tot } 300 \text { a } 410^{\circ} \mathrm{C}\end{array}$ & $\mathrm{TH}<200^{\circ} \mathrm{C}$ \\
\hline
\end{tabular}

Tabela 4. Classificação e caracterização das inclusões fluidas.

Table 4: Classification and characterization of fluid inclusions. 


\section{REFERÊNCIAS BIBLIOGRÁFICAS}

ACHTSCHIN, A.B.; MARCIANO, V.R.P.R.O.; JAVIER RIOS, F 1994. Estudo de inclusões fluidas em berilos do pegmatito Ponte da Raiz, Santa Maria de Itabira, Minas Gerais. In: III Semana de Iniciação Científica da UFMG, Belo Horizonte 1994. Resumos...Belo Horizonte, 119.

BAKAKIN, V.V.; RYLOV, G.M.; BELOV, N.V. 1970. X-Ray diffraction data for identification of beryl isomorphs. Geochemistry International, 7(6): 924-933.

BEUS, A.A. 1960. Geochemistry of beryllium and genetic types of beryllium deposits. Publ. House Acad. Science, Moscovo (em russo).

BILAL, E.; MARCIANO, V.R.P.R.O.; SVISERO, D.P.; CORREIA NEVES,J.M. 1993a. Comparaison entre les columbo-tantalites des pegmatites du nord du Massif de Serra Dourada (Goiás) et celles des pegmatites du centre-ouest de la Province Pegmatitique Orientale (Minas Gerais). In: Congres. Bras. Geoq., 4, Brasília, 1993. Anais ... Brasília, 151-153.

BILAL, E.; MARCIANO, V.R.P.R.O.; RIFFEL, B.F.; SVISERO, D.P.; CORREIA NEVES, J.M. 1993b. Monazitas de pegmatitos da porção centro-oeste da Província Pegmatítica Oriental. In Anais Simp. Geol. de Minas Gerais, 7, Belo Horizonte. Anais ... Belo Horizonte, 12: 99-104.

BODNAR, R.J. \& VITYKL, M.O. 1994. Interpretation of microthermometric data for $\mathrm{H}_{2} \mathrm{O}-\mathrm{NaCl}$ fluid inclusions . In: Short Course of the Working Group (IMA): inclusions in minerals. Pontignano-Siena. De Vivo 8 Frezzotti (eds), 117-130.

CAMERON, E.N.; ROUVE, R.B.; WEIS, P.L. 1951. Fluid inclusions in beryl and quartz from pegmatites of the Middletown District, Connecticut. Am. Mineral. 36: 906-910.

CAMERON, E.N.; ROUVE, R.B.; WEIS, P.L. 1953. Fluid inclusions in beryl and quartz from pegmatites of the Middletown District, Connecticut. Am. Mineral., 38: 218-262.

CASSEDANNE, J.P.; CASSEDANNE, J.O.; ALVES, N.J.; CARVALHO, H.F. 1993. O pegmatito com água - marinha de Ponte da Raiz e suas paragênese Bi- $\mathrm{Pb}-(\mathrm{As})$ (município de Santa Maria de Itabira, Minas Gerais). An. Acad. Bras. Ci., 65 (4) 457-458.

CERNÝ, P. 1975. Alkali variations in pegmatitic beryls and their petrogenetic implicatios. N. Jb. Mineral. Abh., 123: 198-212.

CERNÝ, P. \& BURT, D.M. 1984. Paragenesis, crystallochemical characteristics and geochemical evolution of micas in granite pegmatites. Mineral. Soc. America, Reviews in Mineralogy, 13: 257-297.

COLLINS, P.F.L. 1979. Gas hidrates in CO2-bearing fluid inclusions and the use of freezing data for estimation of salinity. Econ. Geology, 74: 1435-1444

CORREIA NEVES, J.M.; MONTEIRO, R.L.B.P.; DUTRA, C.V. 1984. Composição química de berilos pegmatíticos do Brasil e seu significado petrológico e metalogenético. Rev. Bras. Geoc., 14: $137-146$.

CORREIA NEVES, J.M.; PEDROSA SOARES, A.C.; MARCIANO, V.R.P.R.O. 1986. A Província Pegmatítica Oriental do Brasil à luz dos conhecimentos atuais. Rev. Bras. Geoc. 16 (1): 106118

CRAWFORD, M.L. 1981. Phase equilibra in aqueous fluid inclusions. In: L.S.Hollister and M.L.Crawford (eds). Short course in fluid inclusions: Apllications to petrology. Mineral.Soc. of Canada, 6: 157-181

DRUMOND, J.B.V. 1985. Ipatinga. Folha SE 23 - Z-D. Região Sudeste. In: Projeto mapas metalogenéticos e de previsão de recursos minerais. Texto e mapas: carta metalogenética; carta de previsão de recursos minerais; carta de previsão para planejamento de ações governamentais: DNPM, 15p.

EDIM, N.R.J.; PROCÓPIO, P.M.; OLIVEIRA, J.L.M. 1988. Mapeamento geológico da região de Santa Maria de Itabira e contribuições ao estudo do pegmatito Ponte da Raiz. Trabalho de Graduação. I.G.C. - U.F.M. G. 126p. (inédito).

GOLDSMITH, J.R. \& LAVES, F. 1954. The microcline - sanidine stability relations. Geochim. Cosmochim. Acta, 5: 1-19.

LATHI, S.I. \& KINNUNEN, K.A. 1993. A new gem beryl locality: Luumäki, Finland. Gems \& e Gemology, 30-37.
LOPES NUNES, J.E. 1973. Contribution à l'étude minéralogique et géochimique des pegmatites du Mozambique. Sciences de la Terre, Mím.28: 1-201.

MACEDO, W.A.A.; MARCIANO, V.R.P.R.O.; CORREIA NEVES, J.M.; SVISERO, D.P. 1994. Mössbauer characterization of biotites from zoned pegmatites. Hyperfine Interaction 83: 483487.

MARCIANO, V.P.R.O. 1985. Contribuição ao estudo da mineralogia e geoquímica de pegmatitos da região de Governador Valadares, Minas Gerais. São Paulo, (Dissertação de Mestrado, IG-USP). 213p (inédita).

MARCIANO, V.R.P.R.O; CORREIA NEVES, J.M.; SVISERO, D.P.; QUINTÃO,N.H.; SILVA,L.C.T. 1992a. Pegmatitos do bordo sudeste do Cráton do São Francisco, em Minas Gerais: localização, características morfo-estruturais e mineralogia. In: Simp. Geol. Minas Gerais, 6. Ouro Preto, 1992. Rev. Esc.Minas de Ouro Preto, 45 (1,2): 199-201.

MARCIANO, V.R.P.R.O.; RIFFEL, B.F.; CORREIA NEVES, J.M.;SVISERO, D.P. 1992b. Estudo preliminar de nióbiotantalatos da borda centro-oeste da Província Pegmatítica Oriental. In: Anais do Congr. Bras. Geol., 37. São Paulo, 1992. Anais...São Paulo, SBG_SP, 2: 23-24.

MARCIANO, V.R.P.R.O.; CORREIA NEVES, J.M.; SVISERO, D.P.; CASTILHO, D.L.; ROMEIRO,J.C.; FARIA, L.F. 1992c. Classificação dos corpos pegmatíticos da borda oriental do Cráton Sanfranciscano, através do estudo das moscovitas. In: Anais do Congr. Bras. Geol., 37. São Paulo, 1992. Anais...São Paulo, SBG_SP, 2: 5-6.

MARCIANO, V.R.P.R.O.; SVISERO, D.P.; CORREIA NEVES, J.M. 1993. Dados geocronológicos de pegmatitos da borda oriental do Cráton do São Francisco. In: Simp. sobre o Cráton do São Francisco: sua evolução tectônica e metalogenética, 2. Salvador, 1981, Anais... Salvador, SBG - Ba/SGM, p.362-365.

MENDES, J.C. 1989. Aspectos mineralógicos, geológicos e econômicos da esmeralda de Santa Terezinha de Goiás. São Paulo. (Dissertação de Mestrado, IG/USP) 163p.

PAIVA, G. 1946. Províncias pegmatíticas do Brasil. Rio de Janeiro, DNPM/DFPM. Bol. 78. p.13-21.

ROEDDER, E. 1951. Composition and significance of fluid inclusions in minerals. Geol. Soc. Amer., Bull. 62: 1472.

ROEDDER, E. 1984. Fluid inclusions. Reviews in Mineralogy. Mineral.Soc.Amer. v.12, 644p.

SCHETTINO, A.; MACHADO NETO, O.; GIACROMI, W 1988. Geologia da região de Santa Maria de Itabira (MG). Trabalho de graduação. I.G.C. - U.F.M.G. 72p. (inédito).

SCHOBBENHAUS, C.; ALMEIDA, C.D.; DERZE, G.R.; ASMUS, H.E. 1984. Geologia do Brasil - Texto explicativo do mapa geológico do Brasil e da área oceânica adjacente incluindo depósitos minerais, $501 \mathrm{p}$.

SINKANKAS, J. 1981. Emerald and other beryls Radnor Pennsylvania. Chilton Book Company. 665p.

SMITH, J.V. 1974. Feldspar Minerals, vol 2. Chemical and textural properties. Springer-Verlag, Berlin, 690p.

SOUZA, J.L. 1989. Mineralogia e geologia da esmeralda da jazida de Itabira, Minas Gerais. São Paulo (Dissertação de Mestrado IG-USP), 192p.

SOUZA, J.L. \& SVISERO, D.P. 1987. Estudo óptico e roentgenográfico de inclusão de esmeralda da jazida de Itabira, Minas Gerais. In: Simp. Geol. Minas Gerais, 4, Belo Horizonte, 1987. Anais...Belo Horizonte, SBG, 7: 329-342.

SOUZA, J.L.; MENDES, J.C. \& SVISERO, D.P. 1987. Aspectos mineralógicos e geológicos das esmeralds brasileiras. Rev. Esc. Minas de Ouro Preto, 40(3): 18-26.

SOUZA, J.L.; MENDES, J.C.; SVISERO, D.P.; BELLO, R.M.S.\& VALARELLI, J.V. 1990. Estudos petrográficos e mineralógicos da esmeralda da jazida de Capoeirana, Nova Era, Minas Gerais. In: Congr. Bras. Geol., 36, 1990. Natal. Anais...Natal, SBG, 3: 1389-1402.

TRUEMAN, D.L. \& CERNÝ, P. 1982. Exploration for rare-element granitic pegmatites. In: Cerný (ed.). Granitic pegmatites in science and industry. Miner. Ass. Can. Short Course Handbook, 8: 463-493. 